\title{
Fine structural changes in Sertoli and Leydig cells during the reproductive cycle of the ground squirrel, Citellus lateralis
}

\author{
J. Pudney \\ Department of Biology, Boston University, Boston, MA 02115, U.S.A.
}

\begin{abstract}
Summary. During spermatogenesis in sexually mature ground squirrels Leydig and Sertoli cells were morphologically well differentiated. For Leydig cells the most prominent organelles were lipid droplets, mitochondria with tubulo-vesicular cristae and abundant agranular reticulum organized as a mass of anastomosing tubules. These morphological criteria suggest that the Leydig cells were steroidogenically active. Sertoli cells exhibited a topographical distribution of certain organelles with basal regions containing stacks of granular reticulum, and large areas of agranular reticulum. The cytoplasm surrounding maturing germ cells contained numerous microtubules, and an adluminal layer of spermatids at a certain stage of spermiogenesis became enveloped by Sertoli cytoplasm containing an enormous proliferation of agranular reticulum. The presence of these organelles in Sertoli cells suggests that during spermatogenesis they are active in the synthesis of proteins and steroids. In particular the mass of agranular reticulum surrounding late stage spermatids indicates that steroids may be required for spermatid maturation and/or spermiation. By contrast Leydig and Sertoli cells observed during testicular regression, when only spermatogonia remain in the seminiferous tubules, had undergone structural changes. Leydig cells were still numerous and large with abundant agranular reticulum that was now organized as a loose assemblage of single unbranched tubules. Sertoli cells were drastically reduced in both cytoplasmic volume and content of organelles.
\end{abstract}

\section{Introduction}

The fine structure of Sertoli and Leydig cells has been described for a variety of mammalian species (Sertoli cells: see review by Fawcett, 1975; Leydig cells: see review by Christensen \& Gillim, 1969). Other studies have attempted to relate experimentally induced morphological changes in Sertoli and Leydig cells in common laboratory animals to their functions in regulating spermatogenesis (Dym \& Madhwa Raj, 1977; Flickinger, 1977). Few investigators have utilized the naturally occurring changes that take place in these cells during the reproductive cycle of seasonally breeding animals. Seasonal changes in fine structure of Leydig cells have been reported for a number of species: rock hyrax (Neaves, 1973), bat (Gustafson, 1975), grey squirrel (Pudney \& Lacy, 1977), stone marten Audy, 1978), blue fox (Andersen, 1978) and mole (Suzuki \& Racey, 1978). Similar studies on the Sertoli cell include: the grey squirrel (Pudney \& Lacy, 1977), stone marten (Audy, 1978), bush rat (Rattus fuscipes) (Hodgson, Irby, Kerr \& de Kretser, 1979) and blue fox (Andersen, Sundby \& Hansson, 1981). As yet few detailed accounts exist of the fine structural changes that Sertoli and Leydig cells undergo in the testis of the same seasonally breeding animal. The present study attempts to rectify this by describing the morphological appearance of Sertoli and Leydig cells in the testis of the ground squirrel at different stages of reproductive activity. 


\section{Materials and Methods}

Animals. Male ground squirrels were obtained from southeastern California (Rogers Pet Birds, Rt 2 , Box 60, Shingletown, CA 96086). Sexually mature animals were received in April and May when the testes were spermatogenically active, and in July and August when the testes were regressing.

Microscopy. The histological preparation of tissues for light and electron microscopy has been previously described (Pudney \& Fawcett, 1984). In brief, animals were perfused for $1 \mathrm{~min}$ via the thoracic aorta with physiological saline $(9 \mathrm{~g} \mathrm{NaCl} / 1), \mathrm{pH} 7 \cdot 4$, containing $0 \cdot 1 \%$ procaine hydrochloride, $0.1 \%$ heparin and polyvinylpyrrolidone (mol. wt 40000 ), $2.5 \mathrm{~g} / 100 \mathrm{ml}$. This was followed immediately by a phosphate-buffered mixture of glutaraldehyde $(1.5 \%)$ and formaldehyde $(0.075 \%)$ containing trinitrocresol $(0.075 \%)$ (Forsmann et al., 1977) that was allowed to flow for 10 min. The testes were removed and transverse slices were minced into small cubes and immersed in perfusion fixative for $60 \mathrm{~min}$. Post-fixation was carried out with an aqueous $1: 1(\mathrm{v} / \mathrm{v})$ mixture of $2 \%$ osmium tetroxide and 3\% potassium ferrocyanide (Karnovsky, 1971) for $60 \mathrm{~min}$. The tissue was then dehydrated through a graded series of alcohols and embedded in Epon. Thick and ultrathin sections were cut on a LKB ultramicrotome (Mark 2). Thick sections were stained with toluidine blue for observation by light microscopy. Contrast was enhanced in ultrathin sections by using a saturated solution of uranyl acetate in $50 \%$ alcohol followed by lead citrate. The sections were examined in Philips 200 and JEOL 100S electron microscopes.

\section{Results}

\section{Spermatogenically active animals}

Light microscopy. During spermatogenesis the seminiferous tubules were expanded and filled with germ cells at different stages of development. The seminiferous epithelium, however, was only a few cells deep and did not form well defined layers of successive maturational stages (Fig. 1). Furthermore, spermatogenesis appeared to be synchronized throughout the testis since crosssections showed that most seminiferous tubules contained spermatids at late stages of maturation (see Fig. 1). The interstitial tissue was composed of groups of Leydig cells predominantly located in the interstices among the seminiferous tubules and close to blood vessels (Fig. 1). A well developed lymphatic system is present in the testis of the ground squirrel (Fig. 1).

Electron microscopy. The fine structural appearance of the interstitial tissue is shown in Fig. 2. It contained highly differentiated Leydig cells and many macrophages. Even at this relatively low magnification it was obvious that one of the most prominent organelles present at this stage of the reproductive cycle was the agranular endoplasmic reticulum. This reticulum was organized as a compact network of anastomosing tubules. When these membranes surrounded lipid droplets, they

Fig. 1. Spermatogenically active testis containing seminiferous tubules highly distended with developing germ cells. The seminiferous epithelium is only a few cells deep and the layers of germ cells are not easily identifiable. Most tubules contained a layer of elongate mature spermatids as the most advanced spermatogenic stage. These spermatids were either orientated towards the Sertoli cell nucleus, with their tails and attached residual cytoplasm projecting into the lumen (arrows), or lying within the lumen horizontal to the seminiferous epithelium (arrowheads). The ground squirrel testis has a well developed lymphatic system (asterisks). $\times 270$.

Fig. 2. Low power electron micrograph of interstitial tissue composed primarily of macrophages (M) and Leydig cells (L). Leydig cells contained numerous, often large, lipid droplets, pleomorphic mitochondria and an abundant agranular reticulum. $\times 4000$. 

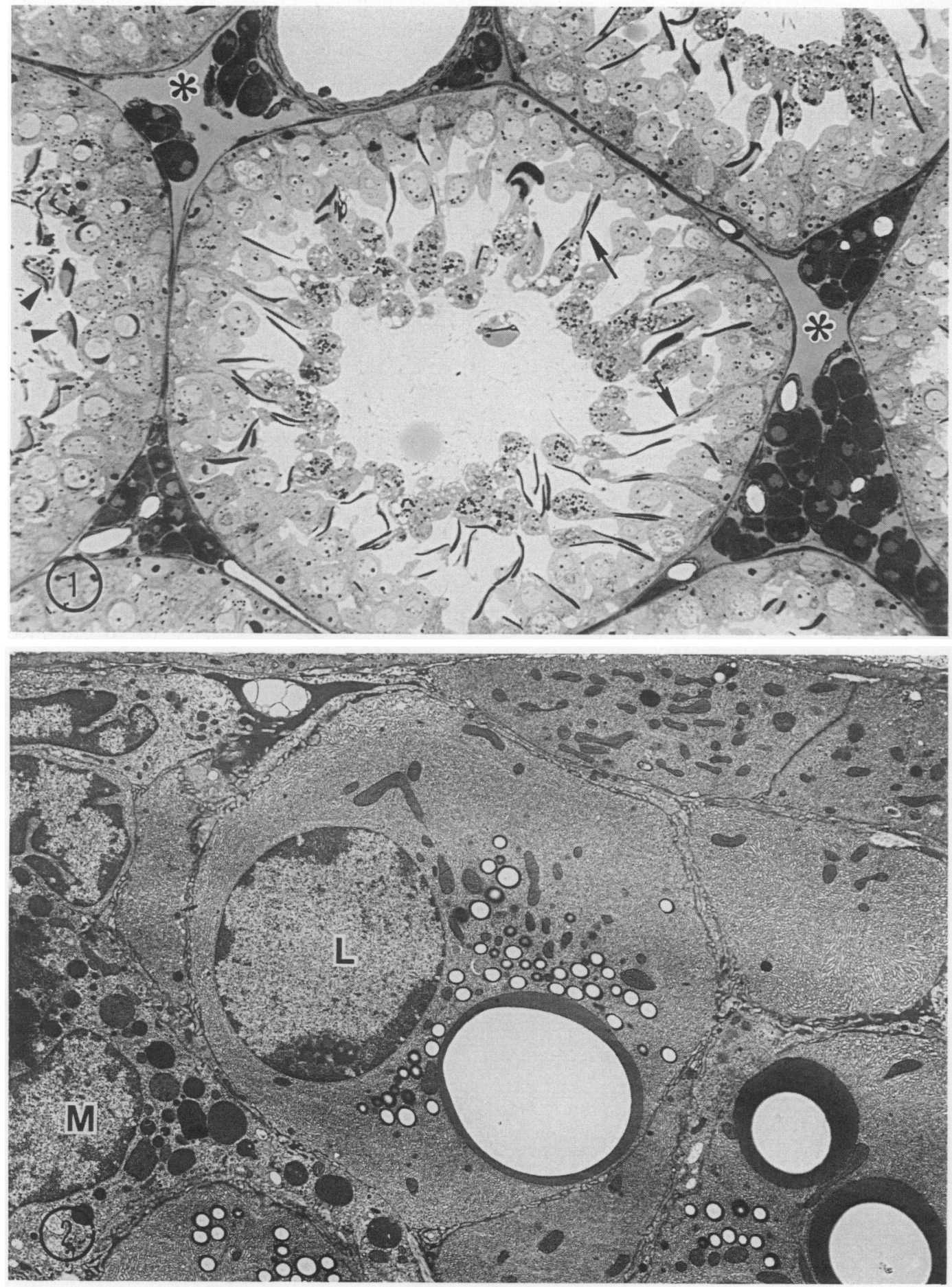

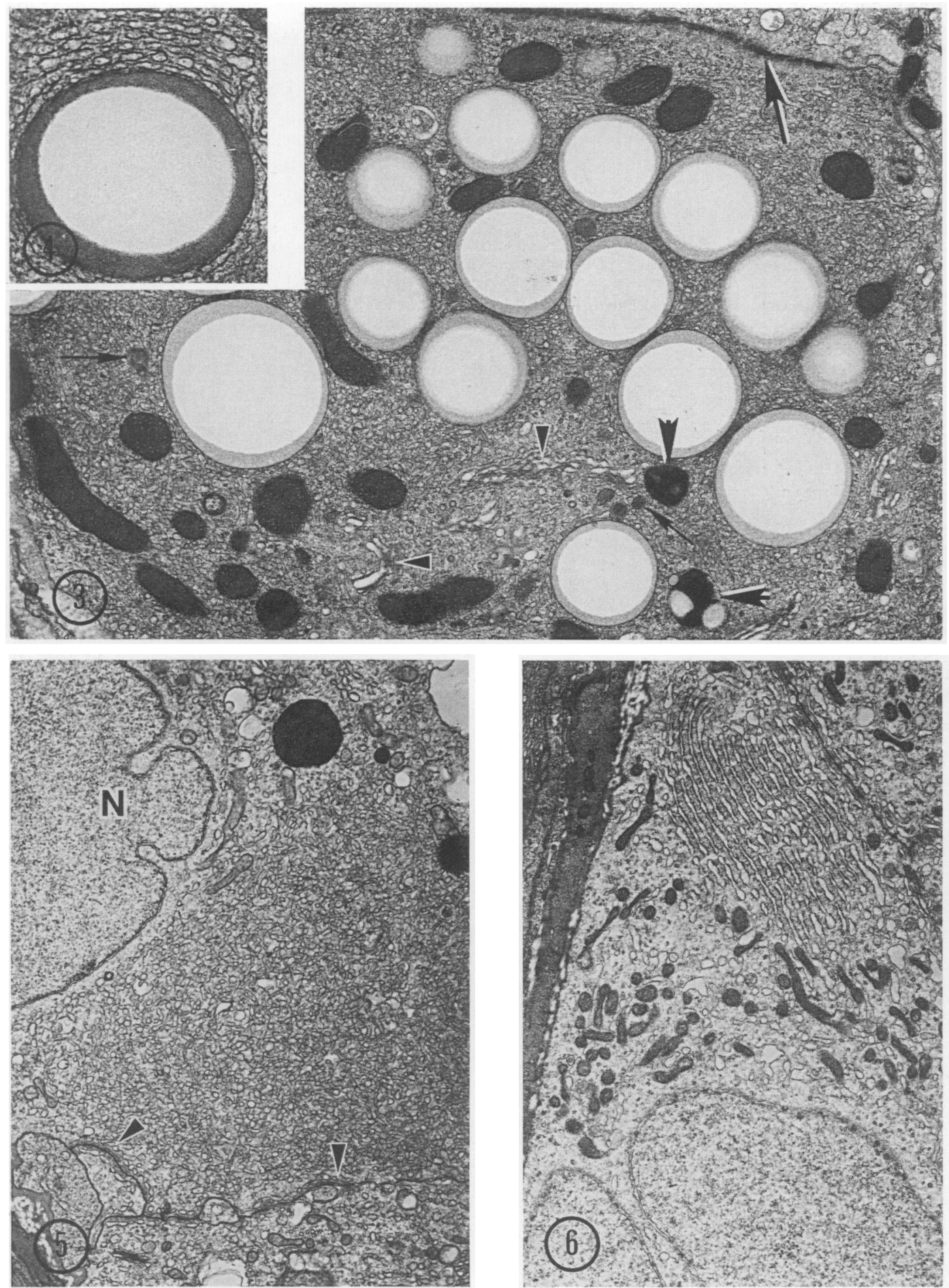
usually formed concentric layers of tubules (Fig. 4). Other structures present at this time included well developed Golgi areas, membrane-limited granules interpreted as peroxisomes, dense inclusions resembling deposits of lipofuchsin material and distinct areas of filaments (Fig. 3). The mitochondria contained numerous tubulovesicular cristae although unusual configurations such as long tubules or paracrystalline arrays of tubules were occasionally present. Adjacent Leydig cells were often connected by extensive gap junctions (Fig. 3).

At the light microscope level the cystoplasm of Sertoli cells was difficult to resolve and it appeared that the adluminal layer of round spermatids was not enclosed by Sertoli cytoplasm (see Fig. 1). When the seminiferous epithelium was examined by means of electron microscopy, it was apparent that Sertoli cytoplasm did extend from the basal lamina of the seminiferous tubule to the lumen to surround these germ cells. However, round spermatids were enveloped by only a thin rim of Sertoli cytoplasm that would have been difficult to detect by light microscopy (see Fig. 9).

Basal areas of Sertoli cells contained highly euchromatic irregularly shaped nuclei surrounded by a layer of fine filaments, large areas of agranular reticulum composed of anastomosing tubules as well as dispersed isolated tubules, and granular reticulum arranged as parallel arrays of cisternae (Figs 5 \& 6). Sections through this region showed several profiles of the Golgi apparatus, indicating that this organelle was multiple and supranuclear in position. Also present were large numbers of polyribosomes and numerous elongate and cup-shaped mitochondria containing mainly tubulovesicular cristae. Lipid droplets were not common in the basal Sertoli cytoplasm, but membranebound granules resembling lysosomes as well as lipofuchsin-like material were often observed. In this region adjacent Sertoli cells were connected by Sertoli/Sertoli occluding junctions (see Fig. 5).

Where elongate spermatids occurred in the seminiferous epithelium, the basal cytoplasm of Sertoli cells often extended towards the lumen as distinct tracts containing mitochondria, tubules of agranular reticulum and numerous microtubules. At this stage of development, the heads of these spermatids were deeply embedded in recesses of this cytoplasm to become closely apposed to Sertoli cell nuclei (see Fig. 1). The tails of these spermatids with attached residual cytoplasm projected into the lumen and did not appear to be surrounded by Sertoli cytoplasm when thick sections were examined with the light microscope. Closer inspection using electron microscopy showed that this was true for the tail region of the spermatids (Fig. 7). Although not contained within Sertoli cytoplasm, the residual cytoplasm remained attached to these cells due to their invasion by several Sertoli cell processes (see Fig. 9). Often residual spermatid cytoplasm was observed within the seminiferous epithelium, with invaginations of Sertoli cell cytoplasm still apparent but now more expanded (Fig. 8). In some cross-sections, seminiferous tubules contained

Fig. 3. Leydig cells also contained several small Golgi areas (arrowheads), membrane-bound granules interpreted as peroxisomes (small arrows), and dense bodies resembling deposits of lipofuchsin (large arrowheads). The agranular reticulum is organized as a tight anastomosing network of tubules. Neighbouring Leydig cells were usually connected by gap junctions (large arrow). $\times 8750$.

Fig. 4. Lipid droplets were often surrounded by concentric layers of tubular agranular reticulum. $\times 30000$.

Fig. 5. Basal areas of Sertoli cells contained euchromatic irregular nuclei (N) and large areas of agranular reticulum. Adjacent basal regions of Sertoli cells developed occluding junctions (arrowheads). $\times 9000$.

Fig. 6. Basal Sertoli cytoplasm also contained stacks of granular reticulum arranged in parallel array and numerous mitochondria. $\times 8000$. 
elongate spermatids whose heads did not plunge deep into Sertoli cytoplasm (Fig. 1). These spermatids, presumably at a different stage of maturation, formed an irregular layer at the apex of the seminiferous epithelium. Electron microscopy showed that these spermatids were connected to the seminiferous epithelium by a stalk of Sertoli cytoplasm. This portion of the Sertoli cell was expanded to enclose the entire acrosomal region of the spermatids. Where this occurred there was a spectacular proliferation of the agranular reticulum in the Sertoli cell cytoplasm adjacent to the acrosome (Fig. 9). This was composed of a mass of branching and anastomosing tubules while a few mitochondria and lipid droplets were situated at the periphery.

\section{Spermatogenically inactive animals}

Light microscopy. Testes of sexually regressed animals were examined at the time of involution when the seminiferous epithelium contained only Sertoli cells and spermatogonia (Fig. 10). By this time the seminiferous tubules were reduced in diameter, no longer had a patent lumen and had noticably thicker boundary layers when compared to sections of spermatogenically active tubules. Degenerating cells, identified by darkly stained cytoplasm and pycnotic nuclei, were present in the seminiferous tubules. The interstitial tissue now completely surrounded the seminiferous tubules and was composed of large Leydig cells containing numerous lipid droplets (Fig. 10). The interstitial lymphatics were not as prominent at this stage as during the period of spermatogenic activity.

Electron microscopy. Although Leydig cells at this stage of sexual regression still appeared large when observed with the light microscope, their fine structural appearance differed from Leydig cells present in the testes of spermatogenically active animals (Fig. 11). The number and variety of their organelles and inclusions appeared diminished, and Golgi areas, membrane-bound granules, lipofuchsin-like material, filamentous areas and extensive gap junctions were seldom observed in these cells. They did, however, contain numerous mitochondria and small lipid droplets. The mitochondria had lamellar as well as tubulovesicular cristae. The unusual arrangements of cristae commonly present in mitochondria of Leydig cells in the spermatogenically active testis were not observed. As during the period of full spermatogenesis, Leydig cells of the involuted testis contained an abundance of agranular reticulum. The configuration of these membranes had changed, however, from a tight anastomosing network of branching tubules to a looser organization comprised predominately of single unbranching tubules (Fig. 11).

Fig. 7. Spermatids with their heads orientated towards the Sertoli cell nucleus have the tail region projecting into the lumen. These tail regions were only partly surrounded by Sertoli cytoplasm (arrowheads). Residual cytoplasm is withdrawn into the Sertoli cell but still remains in contact with the spermatid by means of a thin stalk of cytoplasm (arrow). $\times 10000$.

Fig. 8. Residual bodies (R) were presumably withdrawn into the Sertoli cell by contraction of the Sertoli cell processes (asterisks). This residual body is being released by the Sertoli cell processes. $\times 7200$.

Fig. 9. At the apex of the seminiferous tubule the round spermatids $(\mathrm{Sp})$ in the adluminal layer were enveloped by only a thin rim of Sertoli cell cytoplasm (arrowheads). The elongate spermatids shown here lie in the lumen in a horizontal position in respect to the seminiferous epithelium. These spermatids were attached to the Sertoli cell by a stalk of cytoplasm (arrow). Sertoli cytoplasm surrounding the acrosome of these spermatids developed a spectacular proliferation of the agranular reticulum organized as a mass of anastomosing tubules. The residual bodies contained invaginations of Sertoli cell cytoplasm (asterisks). $\times 6100$. 

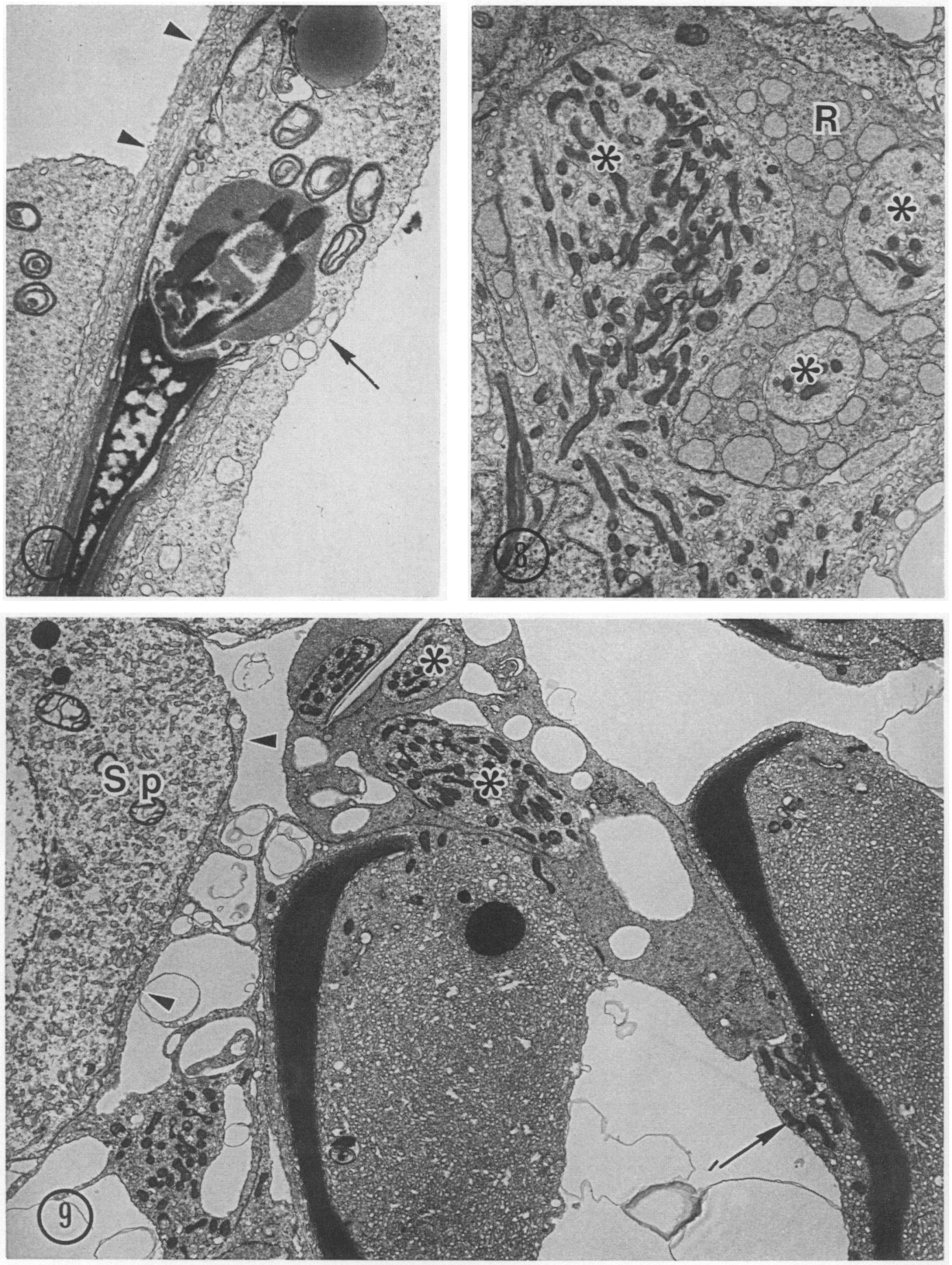

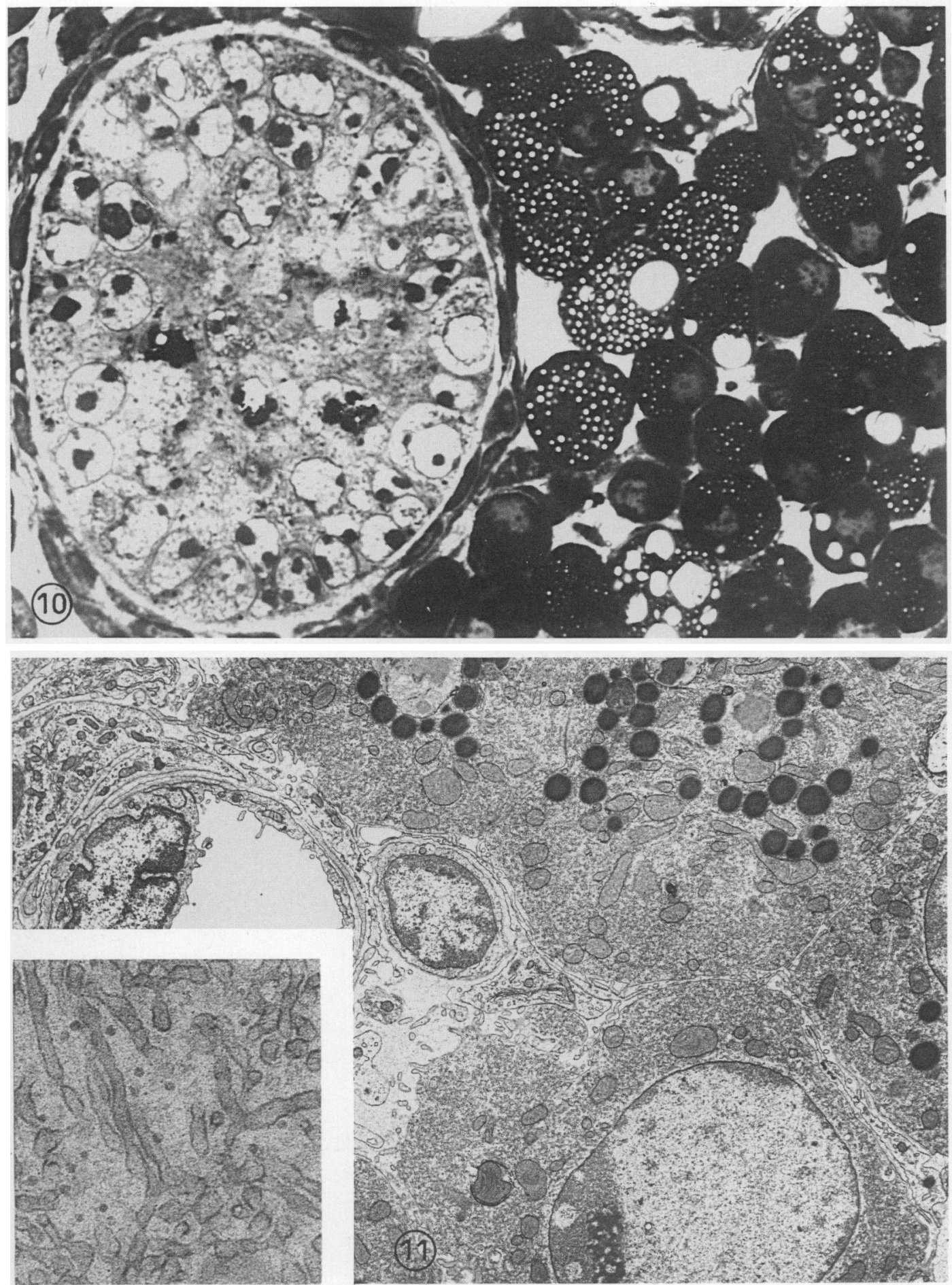
The decrease in tubular diameter resulting from the cessation of spermatogenesis caused the Sertoli cells to become crowded together. This resulted in many Sertoli nuclei becoming displaced from the basal position they occupied during spermatogenesis to lie at a higher level within the seminiferous epithelium (Fig. 12). These nuclei were now regular in outline and contained several large clumps of heterochromatin arranged along the nuclear membrane. The cytoplasmic volume and content of organelles of the Sertoli cells appeared dramatically reduced. The most prominent organelles were many small mitochondria and lipid droplets as well as numerous isolated tubules of the agranular reticulum (Fig. 13). Where several Sertoli cells converged in what would have been the luminal area of the seminiferous tubules, the cytoplasm was expanded and contained a more extensive agranular reticulum (Fig. 14). The Sertoli cells surrounded spermatogonia and these germ cells extended long processes that invaginated the Sertoli cytoplasm (Fig. 14). No specialized junctions between germ cells or neighbouring Sertoli cells were apparent at this stage of testicular involution.

\section{Discussion}

Distinct differences in the morphological appearance of Leydig and Sertoli cells were apparent when observed at different periods of the ground squirrel reproductive cycle.

Leydig cells examined at the time of full spermatogenesis were structurally well-differentiated. Predominant organelles were lipid droplets, mitochondria with tubulovesicular cristae and abundant agranular reticulum. These morphological features are usually associated with high steroidogenic activity and Leydig cells isolated from ground squirrel testes undergoing spermatogenesis contain high levels of enzymes for androgen synthesis (Pudney, Canick, Clifford, Knapp \& Callard, 1985). Large Leydig cells were present in the spermatogenically inactive testis but had undergone some structural changes. The Golgi apparatus was morphologically reduced, and there appeared to be a loss of organelles such as peroxisomes while the unusual arrangements of cristae commonly present in mitochondria during the spermatogenic phase were not apparent. Furthermore, gap junctions were not developed by adjacent Leydig cells. These changes would suggest that during sexual regression there is a reduction of metabolic activity by the Leydig cells that are no longer coupled as functional groups. A surprising feature, however, of these Leydig cells at a time when spermatogonia were the only remaining germ cells in the testis was the abundant agranular reticulum, although its organization had changed, occurring at this time as a loose assemblage of predominantly unbranched tubules. In other species a similar change in organization of the agranular reticulum has been correlated with a reduction in androgen synthesis (Neaves, 1973; Pudney \& Lacy, 1977). Agranular reticulum in this configuration is still capable of steroidogenic activity, however, since Leydig cells isolated from the testes of sexually regressed grey squirrels could readily convert pregnenolone to various hydroxylated pregnanes during in-vitro incubations (Pudney \& Lacy, 1977).

Fig. 10. The regressed testes contained seminiferous tubules composed of Sertoli cells and spermatogonia with occasional degenerating cells. These tubules lacked lumina and the boundary wall was thicker than that surrounding spermatogenically active tubules. The Leydig cells were still large and numerous but now completely surrounded the seminiferous tubules. $\times 220$.

Fig. 11. Low power micrograph of interstitial tissue. Leydig cells contain numerous lipid droplets, and mitochondria. The agranular reticulum still appears abundant but is now more loosely organized than that present in Leydig cells of spermatogenically active testes (compare with Fig. 2 ). $\times 4800$. Insert: The agranular reticulum is predominantly composed of long unbranched tubules that do not anastomose with each other. $\times 52500$. 

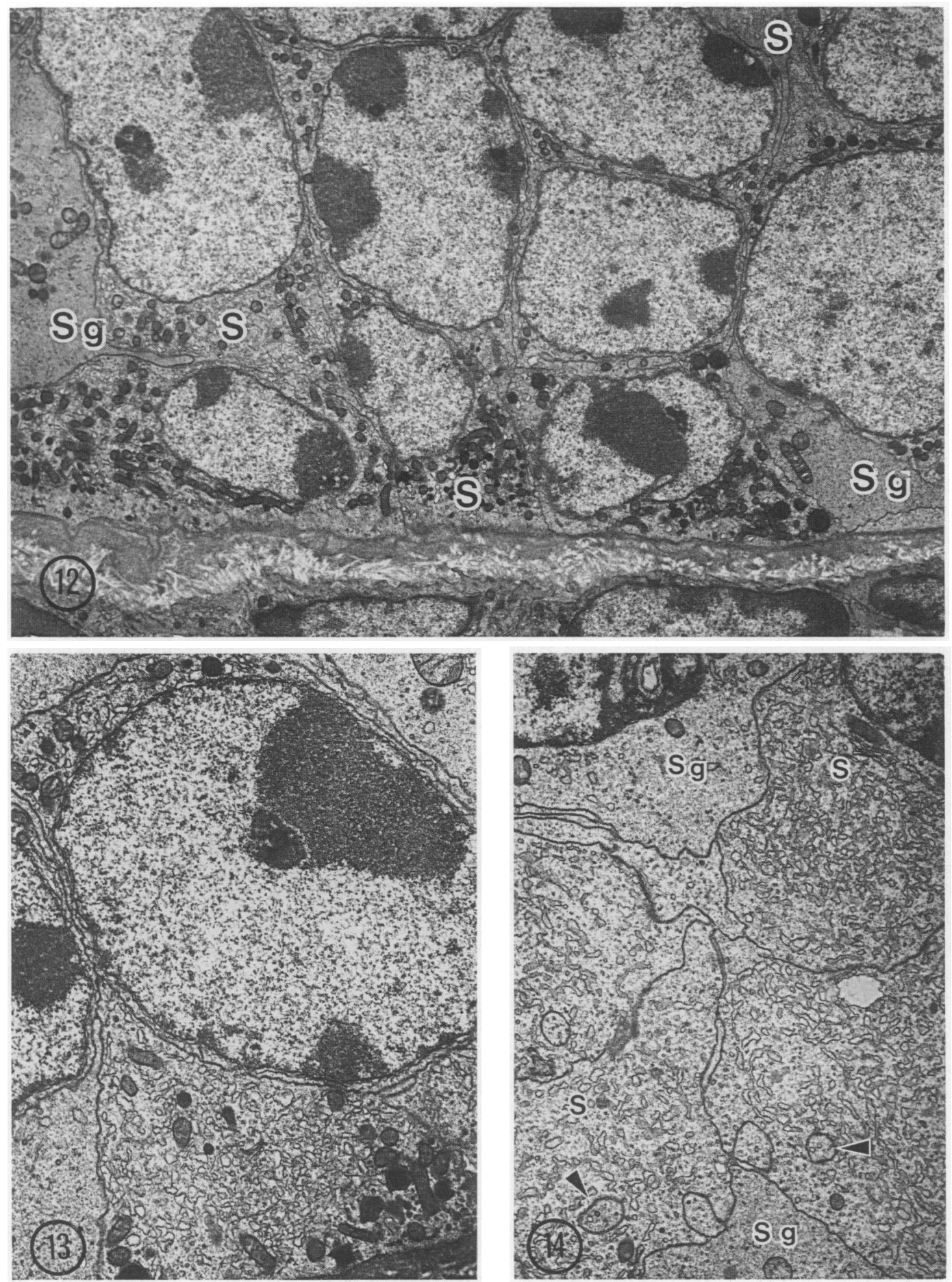
During spermatogenesis Sertoli cells displayed distinct topographical differences in the distribution of certain organelles. Basal regions contained large areas of agranular reticulum, stacks of granular reticulum, numerous mitochondria and multiple Golgi regions. Sertoli cytoplasm extending towards the lumen to surround developing germ cells contained numerous microtubules in addition to mitochondria and tubules of agranular reticulum. An especially conspicuous regional differentiation of Sertoli cytoplasm occurring at a particular stage of spermatid maturation was the formation of a mass of agranular reticulum around the acrosome of these germ cells.

The presence of a well developed granular and agranular reticulum suggests that Sertoli cells are metabolically active in the production of proteins and steroids. Proteins synthesized and secreted by ground squirrel Sertoli cells during spermatogenesis may include protein constituents of seminiferous tubule fluid and possibly specific proteins such as androgen-binding protein (ABP) and inhibin that regulate germ cell development (Hansson et al., 1976; Steinberger \& Steinberger, 1976). Few investigations have determined the presence of ABP in the testes of seasonally breeding mammals (Jegou, Ducheux, Terqui, Garnier \& Courot, 1978; Hodgson et al., 1979). These studies showed that, during the non-breeding season when circulating levels of FSH, LH and testosterone were low, there was a decline in testicular levels of ABP. As yet the presence of inhibin in the testis of a seasonally breeding species during the reproductive cycle has not been investigated. In contrast to Sertoli cells associated with developing germ cells, Sertoli cells of the regressed testis did not contain conspicuous stacks of granular reticulum. This is consistent with a reduced protein secretory function of Sertoli cells at a time when only spermatogonia are present in the seminiferous epithelium. Furthermore, since the regressed seminiferous tubules lacked a patent lumen, it is unlikely that fluid or ABP was being secreted (Tindall, Vitale \& Means, 1975).

The large areas of agranular reticulum seen in Sertoli cells of sexually mature ground squirrels, particularly that surrounding the heads of late stage spermatids, is interpreted as morphological evidence for steroidogenic activity. Moreover, it has been demonstrated that microsomes of isolated tubules prepared from spermatogenically active testes of ground squirrels contain significant levels of enzymes for androgen and oestrogen synthesis (Pudney et al., 1985). These in-vitro data coupled with the morphological appearance of the Sertoli cells of the ground squirrel strongly suggest that these cells have an important steroidogenic function during spermatogenesis, especially during spermiogenesis and/or spermiation. As yet the precise hormonal requirements for spermatid maturation are unknown, although androgen receptors have been detected in nuclei of late spermatids (Wright \& Frankel, 1980). Species that produce ABP as a means for maintaining high androgen levels in the seminiferous epithelium (e.g. rat) do not generally develop extensive amounts of agranular reticulum around late stage spermatids. ABP is also secreted at its highest rate in the rat testis during spermatid elongation and spermiation (Ritzen, Boitani, Parvinen, French \& Feldman, 1982). It is not known whether Sertoli cells of the ground squirrel produce ABP or whether the synthesis of this protein is a widespread feature of the mammalian testis. If ABP is

Fig. 12. At the stage of sexual regression examined the seminiferous epithelium contained only Sertoli cells (S) and spermatogonia $(\mathrm{Sg})$. Due to the shrinkage of the seminiferous tubules after cessation of spermatogenesis many Sertoli cell nuclei became displaced from their basal position to lie deeper within the seminiferous epithelium. $\times 4600$.

Fig. 13. The regressed Sertoli cell was reduced in cytoplasmic volume and content of organelles. The nucleus was regular in outline and contained clumps of heterochromatin arranged along the nuclear membrane. $\times 8000$.

Fig. 14. Where Sertoli cells (S) abutted in the central region of the seminiferous epithelium the cytoplasm was often expanded and contained numerous tubules of agranular reticulum. Sertoli cells were usually invaginated by cytoplasmic processes (arrowheads) of the spermatogonia $(\mathrm{Sg}) . \times 7500$. 
not synthesized by Sertoli cells of the ground squirrel the problem of providing high localized levels of androgen for spermatid development and/or spermiation may have been solved by the production of localized areas of agranular reticulum. A similar dramatic proliferation of agranular reticulum in Sertoli cells associated with mature spermatids has been observed in a non-mammalian vertebrate the spiny dogfish (Squalus acanthias) (Pudney \& Callard, 1984). Furthermore, this proliferation of agranular reticulum could be correlated with the presence of high levels of enzymes for androgen biosynthesis (Callard, Pudney, Mak \& Canick, 1985).

In the ground squirrel the development of the mass of agranular reticulum surrounding late stage spermatids has been investigated by Vogl, Lin, Dym \& Fawcett (1983a). Apparently, the agranular reticulum initially accumulates in a basal position within the Sertoli cell and then migrates towards the lumen to envelop the heads of the spermatids. After spermiation this migration is reversed with the mass of agranular reticulum transported back to a basal location where it becomes dispersed in the Sertoli cytoplasm. It was suggested that the numerous microtubules present in the tracts of Sertoli cytoplasm in which the heads of spermatids were embedded were involved in these movements of the agranular reticulum (Vogl et al., 1983b).

Testicular involution resulted in a structural de-differentiation of Sertoli cells. At the stage of regression when the only remaining germ cells were spermatogonia, there had been a reduction in cytoplasmic volume and content of organelles indicating these cells were not as metabolically active as Sertoli cells during spermatogenesis. The nuclei had become regular in shape and contained large clumps of heterochromatin, changes that are similar to those seen in Sertoli cell nuclei of the rat after passive immunization to LH (Dym \& Madhwa Raj, 1977). The absence of specialized Sertoli/Sertoli occluding junctions at this time could be related to the absence of germ cells beyond the spermatogonial stage.

This investigation was initiated at Harvard Medical School, Department of Anatomy, supported by the Ford Foundation (to J.P.) and Grant HD-02344 Center for Population Studies, National Institutes of Child Health and Human Development (to D. W. Fawcett) and completed at Boston University, Department of Biology, supported by USPHS HD-16715 (J.P.).

\section{References}

Andersen, K. (1978) Seasonal changes in fine structure and function of Leydig cells in the blue fox (Alopex lagopus). Int. J. Androl. 1, 424-439.

Andersen, K., Sundby, A. \& Hansson, V. (1981) Fine structure and FSH binding of Sertoli cells in the blue fox (Alopex lagopus) in different stages of reproductive activity. Int. $J$. Androl. 4, 570-581.

Audy, M.C. (1978) Etude ultrastructurale des cellules de Leydig et de Sertoli au cours du cycle sexual saisonnier de la fouine (Martes foine Fox). Gen. comp. Endocr. 36, 462-476.

Callard, G.V., Pudney, J., Mak, P. \& Canick, J.A. (1985) Stage-dependent changes in steroidogenic enzymes and estrogen receptors during spermatogenesis in the testis of the dogfish Squalus acanthias. Endocrinology 117, 1328-1335.

Christensen, K. \& Gillim, S. (1969) The correlation of fine structure and function in steroid-producing cells with emphasis on those of the gonad. In The Gonads, pp. 415-488. Ed. K. W. McKerns. North Holland, Amsterdam.
Dym, M. \& Madhwa Raj, H.G. (1977) Response of adult rat Sertoli cells and Leydig cells to depletion of luteinizing hormone and testosterone. Biol. Reprod. 17, 676-696.

Fawcett, D.W. (1975) Ultrastructure and function of the Sertoli cell. In Handbook of Physiology: Section 7. Endocrinology; Vol. 5, Male Reproductive System, pp. 21-55. Eds R. O. Greep \& D. W. Hamilton. American Physiological Society, Washington, D.C.

Flickinger, C.J. (1977) The influence of progestin and androgen on the fine structure of the male reproductive tract of the rat. 1. General effects and observations on the testis. Anat. Rec. 187, 405-430.

Forsmann, W.G., Ito, S., Weihe, F., Aoki, A., Dym, M. \& Fawcett, D.W. (1977) An improved perfusion fixation method for the testis. Anat. Rec. 158, 207-222.

Gustafson, A.W. (1975) Observations on the hydroxysteroid dehydrogenase and lipid histochemistry and ultrastructure of the Leydig cells in adult Myotis lucifugus during the annual reproductive cycle. Anat. Rec. 181, 366-367. 
Hansson, V., Weddington, S.C., French, F.S., McLean, W., Smith, A., Nayfeh, S.N., Ritzen, F.M. \& Hagenas, L. (1976) Secretion and role of androgen-binding proteins in the testis and epididymis. J. Reprod. Fert., Suppl. 24, 17-33.

Hodgson, Y.M., Irby, D.C., Kerr, J.B. \& de Kretser, D.M. (1979) Studies of the structure and function of the Sertoli cell in a seasonally breeding rodent. Biol. Reprod. 21, 1091-1098.

Jegou, B., Ducheux, J.L., Terqui, M., Garnier, D.H. \& Courot, M. (1978) Studies of the androgen-binding protein in the rete testis fluid of the ram and its relation to the sexual season. Molec. cell. Endocr. 9, 335-346.

Karnovsky, M.J. (1971) Use of ferrocyanide reduced osmium tetroxide in electron microscopy. Proc. Am. Soc. Cell Biol, 11 th Annual Meeting, p. 146, Abstr. 284.

Neaves, W.B. (1973) Changes in testicular Leydig cells and in plasma testosterone levels among seasonally breeding rock hyrax. Biol. Reprod. 8, 451-466.

Pudney, J. \& Callard, G.V. (1984) Development of agranular reticulum in Sertoli cells of the testis of the dogfish Squalus acanthias during spermatogenesis. Anat. Rec. 209, 311-321.

Pudney, J. \& Fawcett, D.W. (1984) Seasonal changes in fine structure of the ductuli efferentes of the ground squirrel, Citellus lateralis (Say). Anat. Rec. 208, 383-399.

Pudney, J. \& Lacy, D. (1977) Correlation between ultrastructure and biochemical changes in the testis of the American grey squirrel, Sciurus carolinensis, during the reproductive cycle. J. Reprod. Fert. 49, 5-16.
Pudney, J., Canick, J.A., Clifford, N.M., Knapp, J. \& Callard, G.V. (1985) Location of enzymes of androgen and estrogen biosynthesis in the testis of the ground squirrel (Citellus lateralis). Biol. Reprod. 33, 971-980.

Ritzen, F.M., Boitani, C., Parvinen, M., French, F.C. \& Feldman, M. (1982) Stage-dependent secretion of ABP by rat seminiferous tubules. Molec. cell. Endocr. 25, 25-33.

Steinberger, A. \& Steinberger, E. (1976) Secretion of FSH-inhibiting factor by cultured cells. Endocrinology 99, 918-921.

Suzuki, F. \& Racey, S.A. (1978) The organization of testicular interstitial tissue and changes in the fine structure of the Leydig cells of European moles (Talpa europaea) throughout the year. J. Reprod. Fert. 52, 189-194.

Tindall, D.J., Vitale, R. \& Means, A.R. (1975) Androgen binding protein as a marker of formation of the blood-testis barrier. Endocrinology 97, 636-648.

Vogl, A.W., Lin, Y.C., Dym, M. \& Fawcett, D.W. (1983a) Sertoli cells of the golden-mantled ground squirrel (Spermatophilus lateralis): a model system for the study of shape change. Am. J. Anat. 168, 83-98.

Vogl, A.W., Lin, Y.C., Dym, M. \& Fawcett, D.W. (1983b) Colchicine-induced changes in the cytoskeleton of the golden-mantled ground squirrel (Spermophilus lateralis) Sertoli cells. Am. J. Anat. 168, 99-108.

Wright, W.W. \& Frankel, A.I. (1980) An androgen receptor in the nuclei of late spermatids in testes of male rats. Endocrinology 107, 314-318.

Received 30 March 1985 